\title{
Application of Potent Actinomycete Strains for Bio-Degradation of Domestic Agro-Waste by Composting and Treatment of Pulp-Paper Mill Effluent
}

\author{
Lalita Limaye $^{1 *}$, Rajesh Patil ${ }^{1}$, Prafull Ranadive ${ }^{2 *}$, Ganesh Kamath ${ }^{2}$ \\ ${ }^{1}$ Department of Microbiology, Bhavan's College, Mumbai University, Mumbai, India \\ ${ }^{2}$ Research and Development Department, Organica Biotech Pvt. Ltd., Govandi, Mumbai, India \\ Email: *lalitalimaye@yahoo.co.in, *prafull@organicabiotech.com
}

How to cite this paper: Limaye, L., Patil, R., Ranadive, P. and Kamath, G. (2017) Application of Potent Actinomycete Strains for Bio-Degradation of Domestic AgroWaste by Composting and Treatment of Pulp-Paper Mill Effluent. Advances in Microbiology, 7, 94-108.

http://dx.doi.org/10.4236/aim.2017.71008

Received: December 9, 2016

Accepted: January 17, 2017

Published: January 20, 2017

Copyright $\odot 2017$ by authors and Scientific Research Publishing Inc. This work is licensed under the Creative Commons Attribution International License (CC BY 4.0).

http://creativecommons.org/licenses/by/4.0/

(c) $\underset{\mathrm{EY}}{\mathrm{i}}$ Open Access

\begin{abstract}
Actinomycetes are known to produce an extensive range of bioactive compounds as well as variety of enzymes having multiple biotechnological applications. They are an important source of lignocellulose hydrolyzing enzymes and constitute considerable proportion of the soil or aquatic micro-flora responsible for degradation of biomass in natural environment. Presently, most of the commercially exploited lignocellulases and commercial biodegradation processes rely mostly on fungal or bacterial micro-organisms. Actinomycetes are relatively less explored for biodegradation processes that utilize lignocellulases for solid agro-waste management and waste water treatment. There is also a need to search and explore novel actinomycete strains for various biodegradation applications. This study involved examining the possibility of using only potent actinomycetes strains for the composting process by creating the consortium of such strains that could produce thermo-tolerant and alkali-tolerant key enzymes necessary for the degradation of cellulose, hemi-cellulose and lignin. The newly developed actinomycete consortium was tested for the composting activity and the composting process was optimized. The analysis of the composted material generated under ideal condition, demonstrated desirable physical and chemical characteristics. Paper pulp effluent poses a hazard to waterways due to toxicity. The toxicity of this mill effluent can be attributed to a compound called lignin and its chlorinated derivatives that are let out during the treatment of lignocellulosic constituents. Current study also involves the use of a strain of actinomycete having ability to produce enzyme laccase, which is active under alkaline condition for the treatment of paper pulp effluent. Enzyme laccase is known for its ability to attack phenolic components of lignin and common hazardous component of effluent, polycyclic aromatic hydrocarbons (PAH). Aerobic treatment of effluent by actinomycete strain indicated $21 \%$ reduction in COD at $\mathrm{pH} 7.5$ after 14 days under optimum condition. This strain was identified as Streptomyces rochei based on molecular fingerprinting
\end{abstract}


and was reported to be the producer of laccase probably for the first time. LCMS analysis of the treated effluent sample showed the presence of degradation compounds forming after 7 and 14 days of treatment. These compounds showed the degradation of lignin components and other phenolic, non-phenolic components of the effluent by intra molecular re-arrangement, oxidation and ring opening reactions. Overall, potent thermo-tolerant and alkali-tolerant actinomycete strains were successfully isolated and applied for bio-degradation of domestic agro-waste by composting and treatment of pulp-paper mill effluent. The consortium of these strains may be further utilized for scale-up studies in order to assess its commercial feasibility for biodegradation processes.

\section{Keywords}

Biodegradation, Consortium, Actinomycetes, Composting, Thermo-Tolerant, Alkali-Tolerant

\section{Introduction}

Composting helps in organic amendment to the soil for improving its physical, chemical and biological properties [1]. It is a natural process and can be accelerated by the use of the correct mixture of micro-organisms [2] [3]. The process involves rapid succession of mixed microbial populations. As per the prevailing process, the main groups of microorganism involved are bacteria, including actinomycetes and fungi [4] [5]. Composting can be broadly divided into three stages [6] [7] [8]. In the initial stage, simple organic molecules like sugars and proteins are degraded resulting drop in $\mathrm{pH}$ and rise in temperature [9] [10]. Thermo-tolerant and thermophilic population dominates the middle phase, producing enzymes responsible for degradation of complex organic material and temperature rises further. Concluding stage of the composting is characterized by the growth of actinomycetes and fungi that degrade the most complex organic matters under high temperature and high $\mathrm{pH}$ environment [11] [12]. Raw material used for composting is ligno-cellulosic biomass. Ligno-cellulosic materials are mainly composed of cellulose (35\% - 50\%), hemicellulose (15\% - 35\%) and lignin (10\% - 35\%) [13]. All three components have very close interactions with each other. Composting involves breakdown of all three components with the use of microbial enzymes. The set of enzymes indispensably involved in the process are laccases, xylanases and cellulases. Laccase enzyme removes the cementing material by lignin degradation and xylanase acts on xylan; hemicellulose component keeps the cellulose fibers together [14]. Once lignin and hemicellulose are eliminated, cellulose fibers are left open for cellulase to attack, thus, breaking down the final component of ligocellulose during composting. All three enzymes act in association and in sequence to produce mature compost [15]. Produced manure serves a dual purpose of management of solid waste and amendment to soil as well.

Parallely, bioremediation is one of the hot areas in research because of the increased level of toxicants added to the environment. Due to numerous potential threats posed by waste, discarded by industries, several countries across the globe have set a limit on 
the quantity of untreated fluids discharged into rivers, lakes and oceans. Due to the expenses involved, various remedies to these problems have been put forth, but not brought into effect. Biological and well as physiochemical treatments are being taken into consideration in order to minimize capital and operating expenditure. Aiming at minimized emission of toxicants into nature, biotechnological research is a promising economical solution to the thermal problems, increased BOD/COD and other ecological concerns in the future.

One of the chief hazards posed to waterways is nowadays created by the pulp and paper industry. This hazard is in the form of a dark coloured effluent (either brown or black) which is a primary result of the main stages of the production process; namelypulping, bleaching and paper making. The dark color of the liquid waste obstructs rays of sunlight from entering the water, which reduces respiration as well as photosynthesis. The paper pulp organic effluents directly or indirectly affect not only the environment, but also human life. Exposure to such contaminated water by means of drinking or cooking can lead to the contraction of several dangerous diseases. Another way in which damage to health may occur is by consumption of the fish thriving in such an unclean surrounding [16].

Amongst the enzymes employed for composting, laccase enzyme has a great potential to be also used for bioremediation but is still less explored for the same. Laccase (benzenediol: oxygen oxidoreductases, E.C 1.10.3.2) is a multi-copper enzyme belonging to the group of blue oxidases. Laccase is described as oxidoreductase in Enzyme Commission (EC). Laccase enzyme catalyzes mono-electronic oxidation of a broad spectrum of substrates. The substrates include ortho- and para-diphenols, polyphenols, aminophenols and aromatic or aliphatic amines. Oxidation of substrate is coupled with four-electron reduction of $\mathrm{O}_{2}$ to $\mathrm{H}_{2} \mathrm{O}$. Enzyme laccase is known for its ability to attack phenolic components of lignin and common hazardous component of effluent, polycyclic aromatic hydrocarbons (PAH). Therefore, this enzyme has been considered to play a significant role in the bioremediation actinomycetes; bacteria growing in the form of filaments are packed with all the enzymes needed for composting as well as bioremediation. Their filamentous morphology facilitates the penetration and spreading all over the organic matter during growth, leading to efficient degradation of the material. Moreover, they are also responsible for the release of enzymes extracellularly that degrade cellulose, hemi-cellulose and lignin [16].

The present study dealt with the isolation of the potent actinomycete strains which could be useful in biodegradation of domestic waste via composting. The study also simultaneously explored the potential of the same cultures for treatment of paper pulp effluent. Much of the research has been carried out to solve both the purposes of composting as well as remediation; however, most of them were with the use of either bacteria or fungi. This study was novel in terms of opening avenues for exploration of actinomycetes to serve the purpose of solid as well as liquid waste management.

\section{Materials and Methods}

\subsection{Isolation of Actinomycete Strains}

Sediment samples were collected from various locales. Sites for the sample collection 
could be categorized into: marine environment, mangroves, hot water spring, compost, river and lake sediments and soil. Sample collection was done using alcohol sterilized spatula and samples were stored in sterile screw capped bottles. Sample treatment involved air drying for 48 hours, homogenizing in mortar and pestle followed by sieving. After treatment all the samples were diluted appropriately with saline except for marine and mangrove samples which were diluted using 1:2 diluted sea water. Actinomycete Isolation Agar at pH 8 (M490 HiMedia laboratories) was used for the isolation of actinomycetes from the sediment samples. Antibiotics Cycloheximide $-50 \mu \mathrm{g} / \mathrm{ml}$ and Streptomycin $100 \mu \mathrm{g} / \mathrm{ml}$ were added to the medium. Plates were incubated at $40^{\circ} \mathrm{C}$ and checked for growth. Incubation period varied from 1 - 3 weeks. Actinomycete colonies were identified by their morphological characteristics and microscopy. Isolation medium with $\mathrm{pH} 8$ and incubation temperature of $40^{\circ} \mathrm{C}$ were maintained to make sure that alkali-tolerant and thermo-tolerant actinomycete strains could be isolated.

ISP 4 medium was used for the sporulation of the cultures. Spore suspension of $10^{5}$ spores $/ \mathrm{ml}$ was prepared in saline for all the strains as a standard inoculum.

\subsection{Screening of Strains for Enzyme Production}

All the strains were screened for xylanase and laccase production. Xylanase and laccase producing strains were shortlisted and screened further for cellulase activity. Enzyme production medium with $\mathrm{pH} 8$ and incubation temperature of $40^{\circ} \mathrm{C}$ were maintained to make sure that enzymes produced displayed alkali-tolerance and thermo-tolerance.

\subsubsection{Screening for Xylanase Producers}

Qualitative plate assay was carried out using wheat bran agar. Wheat bran agar composition in (g/l) - wheat bran 20 (digested and strained through muslin cloth), Peptone 5, Beef extract 3, Agar 20.

$10 \mathrm{ul}$ of spore suspension was spot inoculated on the medium. After 5 days of incubation at $40^{\circ} \mathrm{C}$, agar surface was covered with $1 \%$ Congo red solution for 15 minutes. Excess Congo red was poured off and the plate was overlaid with $1 \mathrm{M} \mathrm{NaCl}$ for 1 hour. Zone of clearance indicated xylanase activity. Cultures were selected on the basis of $\mathrm{Cx}$ ratio. Standard culture used was Streptomyces sp. NCIM 5027.

\subsubsection{Screening for Cellulase Producers}

Qualitative plate assay was carried out using CMC agar. CMC agar composition in (g/l) - Carboxy-methyl cellulose (CMC-a soluble form of cellulose) 5, $\mathrm{NaNO}_{3} 1$, $\mathrm{K}_{2} \mathrm{HPO}_{4} 1, \mathrm{KCl} 1, \mathrm{MgSO}_{4} 0.5$, yeast extract 0.5 , glucose 1 and agar 20.

$10 \mu \mathrm{l}$ of spore suspension was spot inoculated on the medium. After 5 days of incubation at $40^{\circ} \mathrm{C}$, agar surface was covered with $1 \%$ Congo red solution for 15 minutes. Excess Congo red was poured off and the plate was overlaid with $1 \mathrm{M} \mathrm{NaCl}$ for 1 hour. Zone of clearance indicated cellulase activity. Cultures were selected on the basis of Cx ratio.

\subsubsection{Screening for Laccase Producers}

Qualitative laccase plate assay was carried out using basal agar with trace solution and $0.01 \%$ guaiacol. 
Composition of the basal agar $(\mathrm{g} / \mathrm{l})-\left(\mathrm{NH}_{4}\right)_{2} \mathrm{SO}_{4}-2, \mathrm{~K}_{2} \mathrm{HPO}_{4}-1, \mathrm{KH}_{2} \mathrm{PO}_{4}-0.5$, $\mathrm{MgSO}_{4}-0.2$, yeast extract -1 , Maltose $200 \mathrm{mM}$, Asparagine 0.2 and agar 20. Asparagine is added as the source of organic nitrogen. Sterile trace solution $0.1 \% \mathrm{v} / \mathrm{v}$ was added to the basal medium after autoclaving. $0.01 \%$ guaiacol dissolved in ethanol was added before autoclaving.

Composition of the trace solution $(\mathrm{g} / \mathrm{l})-\mathrm{CuSO}_{4} \cdot 7 \mathrm{H}_{2} \mathrm{O}-0.025, \mathrm{ZnSO}_{4} \cdot 7 \mathrm{H}_{2} \mathrm{O}-0.3$, $\mathrm{MnCl}_{2} \cdot 5 \mathrm{H}_{2} \mathrm{O}-0.2, \quad \mathrm{MgSO}_{4} \cdot 7 \mathrm{H}_{2} \mathrm{O}-2.5, \quad \mathrm{CaCl}_{2} \cdot 2 \mathrm{H}_{2} \mathrm{O}-1.5, \quad \mathrm{FeSO}_{4} \cdot 7 \mathrm{H}_{2} \mathrm{O}-0.25$ and $\mathrm{COCl}_{2} \cdot 6 \mathrm{H}_{2} \mathrm{O}-0.05$. Trace solution was sterilized separately by autoclaving.

$10 \mu \mathrm{l}$ of spore suspension was spot inoculated on the medium and incubated for 5 days. Positive laccase activity was indicated by the reddish brown halo formed around the colony when guaiacol was incorporated in the medium.

\subsection{Composting}

8 strains selected for the formation of consortium were designated as: C1, C3, C4, C5, F, $\mathrm{T}, \mathrm{R}$ and L11. These strains were used as the seed culture for composting.

\subsubsection{Inoculum Build Up}

Selected strains were grown at $40^{\circ} \mathrm{C}$ for 96 hours on ISP 4 medium for good sporulation. For each strain, spore suspension was prepared in saline with $0.01 \%$ Tween 80 .

\subsubsection{Formulating the Consortium of Selected Strains}

Total viable count of each spore suspension was detected and adjusted to $1 \times 10^{9}$ spores/ml. Plate Count Agar (M091 HiMedia laboratories) was used for carrying out the viable count. Pooled spore suspension was prepared by adding $100 \mathrm{ml}$ spore suspension of each isolate.

\subsubsection{Composting Unit}

Compost units of dimensions $35 \mathrm{~cm} \times 25 \mathrm{~cm} \times 40 \mathrm{~cm}$ (length $\times$ width $\times$ height) got fabricated (Figure 1). Fruit and vegetable waste acquired from the local market was shredded and used as a raw material for composting. 300 gms of waste was added in each compost unit. 50 gms of dried banana leaves were added in the unit to facilitate aeration and avoid raw material compacting. $300 \mathrm{ml}$ of consortium was added to the

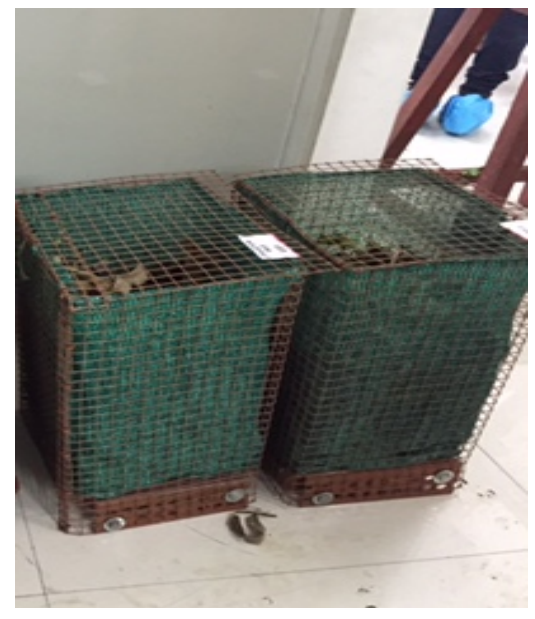

Figure 1. Composting unit. 
composting unit and mixed uniformly throughout the raw material. Un-inoculated control was maintained with $300 \mathrm{ml}$ of saline mixed with the raw material.

\subsubsection{Maintaining the Moisture Level}

Composting units were kept in the shade. Composting was allowed to take place for 25 days. Moisture level was maintained by addition of $20 \mathrm{ml}$ water to the pile everyday. Pile was turned once in a week to ensure the aeration.

\subsubsection{Analysis of the Composted Material}

Norms laid by National Centre of Organic Farming, Department of Agriculture, Government of India were followed for the analytical study. Following parameters were studied:

1) Estimation of $\mathrm{pH}$

2) Estimation of moisture;

3) Estimation of conductivity;

4) Estimation of organic carbon;

5) Estimation of total nitrogen;

6) Estimation of C:N ratio.

\subsection{Effluent Treatment}

\subsubsection{Acclimatization of the Selected Strain}

Strains selected on the basis of enzyme production were grown on Nutrient agar $(\mathrm{pH}$ 7.5) with $10 \%$ effluent added before sterilization. This is to check the ability of the strains to grow in the presence of effluent.

Paper pulp effluent was treated with laccase producing strain of actinomycete designated as $\mathrm{R}$.

\subsubsection{Treatment of the Effluent Sample and Inoculation with Strain $\mathbf{R}$}

Effluent sample was received from the paper pulp industry. Sample was autoclaved before beginning of the study.

Sample was diluted $1: 2$ with sterile distilled water. $0.1 \%$ dextrose and $0.1 \%$ peptone were added to the effluent sample as $\mathrm{C}$ and $\mathrm{N}$ sources respectively. $\mathrm{pH}$ was adjusted to 7.5 with $1 \mathrm{~N} \mathrm{NaOH}$. The spore suspension of the isolated streptomyces strain $\mathrm{R}$ was prepared in saline with $0.01 \%$ Tween 80 by scrapping the sporulated growth on ISP 4 agar medium. $5 \%$ spore suspension of density $10^{5}$ spores $/ \mathrm{ml}$ was used as the inoculum. Inoculated sample was kept under aeration by introducing a continuous stream of bubbles with the help of air pump.

Incubation was done at room temperature with continuous aeration.

Readings were taken on day zero, Day 7 and Day 14.

\subsubsection{Parameters Studied during Effluent Treatment}

1) Colour: Measurement was done with HI83099 multi parameter photometer. Sample was filter sterilized before colour measurement to remove the particulate matter which could interfere with the "true colour" reading. Colour was expressed in terms of "platinum cobalt units (PCU)" which is a recommended nomenclature for referring to the colour of organic liquids under "Platinum-Cobalt Colour" (Standard Methods for 
the Examination of Water and Wastewater, 18th edition, Colourimetric Platinum Cobalt method).

2) COD: Sample was diluted 1:10 with sterile distilled water. Diluted sample was digested in HANNA COD reactor (HI 839800). $0.2 \mathrm{ml}$ sample was added in each vial of reactants for digestion, provided with the instrument. COD was read by using HANNA HI83099 COD photometer (USEPA 410.4)

3) LC MS: In order to monitor the degradation of compounds in effluent, LC-MS analysis of treated and untreated effluent sample was carried out after 7 and Day 14 of the treatment. The Agilent Mass Quadrupole Time-of-Flight (Q-TOF) LC/MS system was used to detect compounds of MS Min Range (m/z) 100 to MS Max Range (m/z) 3000. High Performance Chip, $360 \mathrm{nl}$ enrichment column, $150 \mathrm{~mm} \times 75 \mathrm{~A} \mu \mathrm{m}$ separation column was used with gradient mode acetonitrile-water mobile phase having run time of $60 \mathrm{~min}$ and flow rate of $0.30 \mu \mathrm{L} / \mathrm{min}$.

\subsubsection{Phylogenetic Identification of Alkali Tolerant Laccase Producing Strain $\mathbf{R}$}

DNA was isolated from the active strain grown in ISP2 (International Streptomyces Project Medium 2) containing [dextrose $4 \mathrm{~g} / \mathrm{L}$, yeast extract $4 \mathrm{~g} / \mathrm{L}$, malt extract $10 \mathrm{~g} / \mathrm{L}$, made in $75 \%$ ASW, $\mathrm{pH} 7.0$ to 7.5]. DNA from washed cell suspension was extracted using Ultraclean TM Tissue and Cells DNA Isolation kit, Mo Bio Laboratories, Inc. PCR-mediated amplification of 16S rRNA gene was carried out using 16S universal primers: 8F (AGAGTTTGATCCTGGCTCAG), 1492R (ACGGCTACCTTGTTACGA CTT) and BDTv3.1 Cycle sequencing kit on ABI 3730x1 Genetic Analyzer. The near complete $16 \mathrm{~S}$ rRNA sequence (1156 bp) was desired and aligned with corresponding first ten matching sequences. The program CLUSTALW2 (www.ebi.ac.uk/Tools/msa/clustalw2/) was used for both multiple alignment and phylogenetic analyses. Based on maximum identity score, first ten sequences were selected and aligned using multiple alignment software program Clustal W. Distance matrix was generated using RDP database and phylogenic tree was constructed using MEGA6.

\section{Results and Discussion}

Enzyme production medium with $\mathrm{pH} 8$ and incubation temperature of $40^{\circ} \mathrm{C}$ were maintained for all enzyme assays. Selection of the strains was such that all the strains produced enzymes which displayed alkali-tolerance and thermo-tolerance.

\subsection{Screening of Xylanase and Cellulase Producers}

Actinomycete strains were selected on the basis of their ability to produce xylanase, cellulase and laccase enzymes. Potent xylanase producers were shortlisted and screened further to check their ability to produce cellulase. Selection of strain was done in such a way that all the shortlisted isolates had the ability to produce either one enzyme in large quantity or both the enzymes in moderate quantities. Extent of enzyme production was decided on the basis of $\mathrm{Cx}$ ratio. $\mathrm{Cx}$ ratio is the ratio of diameter of zone of clearance to the diameter of colony.

\subsection{Screening of Laccase Producers}

Laccase enzyme expression is not very common in actinomycetes. All 45 strains were 
screened for laccase producer. Two strains were found to be laccase positive.

\subsection{Consortium of Selected Strains}

Out of 45 strains screened, 8 strains were shortlisted for the consortium. Table $1 \& \mathrm{Ta}$ ble 2 present the details of the shortlisted strains. Figure 2 shows the growth pattern of few selected strains on ISP 4.

All the selected strains produced enzymes which were thermo-tolerant and alkalitolerant.

Table 1. Selection of the potent xylanase producers on the basis of $\mathrm{Cx}$ ratio compared with standard culture Streptomyces sp. NCIM 5072.

\begin{tabular}{cc}
\hline Strain & Cx ratio on Wheat bran agar \\
\hline C1 & 2.3 \\
C3 & 1.7 \\
C4 & 2 \\
C5 & 2.1 \\
F & 1.8 \\
T & 2.3 \\
R & 2 \\
L11 & 1.6 \\
& 1.6 \\
\hline
\end{tabular}

Inoculum size: $1 \times 10^{5}$ spores $/ \mathrm{ml} ; 10 \mathrm{uL}$ inoculum spot inoculated; incubation at $40^{\circ} \mathrm{C}$ for 5 days.

Table 2. Enzyme activity displayed by 8 strains used for consortium.

\begin{tabular}{cccc}
\hline Strain & Xylanase activity & Cellulase activity & Laccase activity \\
C1 & + & ++ & - \\
C3 & ++ & + & + \\
C4 & ++ & + & - \\
C5 & ++ & ++ & - \\
F & + & ++ & - \\
T & + & + & + \\
R & ++ & + & + \\
L11 & + & +
\end{tabular}

Key: “+” good activity, “+ +” very good activity, “-” no activity.
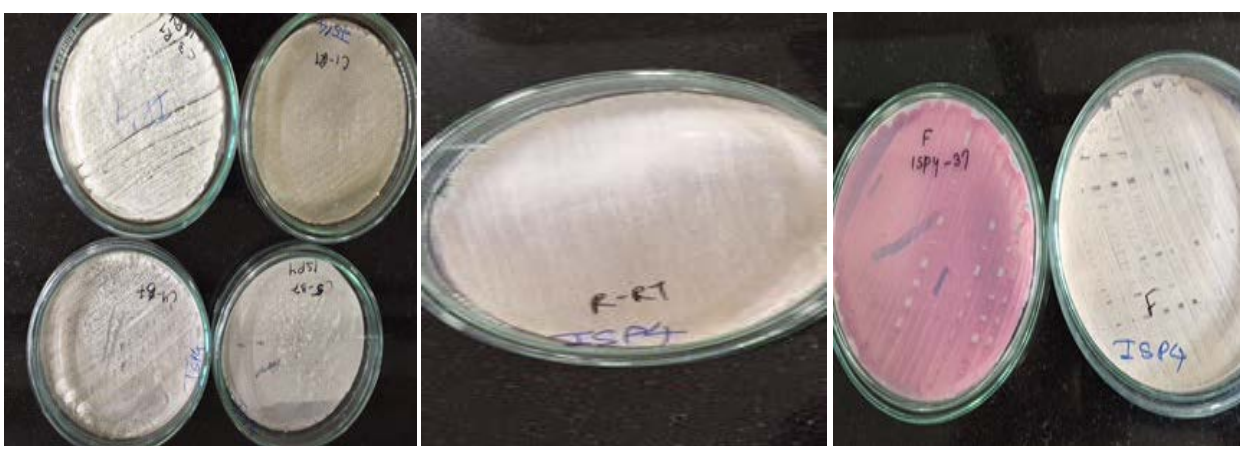

Figure 2. Growth pattern of few selected strains on ISP 4 . 
Composting was carried out for 25 days. Study of the following parameters was done to understand the efficiency of composting process.

\subsection{Compost Analysis}

i) Compactness was measured in terms of the height of the compost pile (refer to Table 3).

ii) Study of physical and chemical characteristics of the composted material. Results were interpreted by referring to FCO (Fertilizer Control Order) specifications (refer to Table 4).

Specifications of Organic Fertilizers given in Part A, Schedule IV of National Centre of Organic, Farming (NCOF) Department of Agriculture and Cooperation, Ministry of Agriculture, Government of India have been followed.

Composted material showed physical and chemical characteristics in the desired range. $\mathrm{C} \%$ and $\mathrm{N} \%$ observed in the composted material are higher, but the C:N ratio was observed falling in the required range. Variations in the values of $\mathrm{C} \%$ and $\mathrm{N} \%$ could be due to the type of raw material used. By referring to the NCOF guidelines it was observed that since physical as well as chemical characteristics are in the desired range, this product can be used as a soil amendment.

\subsection{Selection of the Strain for Effluent Treatment}

Out of 8 strains, only one strain designated as $\mathrm{R}$ could grow on Nutrient agar $\mathrm{pH} 7.5$

Table 3. Measurement of compactness of the compost pile.

\begin{tabular}{ccc}
\hline Compost unit & Initial height $(\mathrm{cm})$ & Final height $(\mathrm{cm})$ \\
\hline Control unit & 26 & 16 \\
Consortium unit & 25.5 & 8.5
\end{tabular}

Table 4. Study of physical and chemical characteristics of the composted material.

\begin{tabular}{|c|c|c|}
\hline Test parameters & Consortium & Control \\
\hline \multicolumn{3}{|l|}{ Physical characteristics } \\
\hline Texture & Heterogeneous material & Heterogeneous material \\
\hline Colour & Brown to black & Brown to black \\
\hline Odour & No foul smell & No foul smell \\
\hline Moisture (\%) & 23.98 & 18.68 \\
\hline $\begin{array}{l}\text { Particle size ( } \mathrm{min} 90 \% \\
\text { through } 4 \mathrm{~mm} \text { is sieve) }\end{array}$ & 13.3 & 18.5 \\
\hline \multicolumn{3}{|l|}{ Chemical characteristics } \\
\hline Maturity & Mature & Mature \\
\hline $\mathrm{pH}(1: 2)$ & 7.57 & 7.5 \\
\hline $\begin{array}{l}\text { Electrical conductivity } \\
\qquad(\mathrm{ds} / \mathrm{m})(1: 5)\end{array}$ & 4.6 & 4.2 \\
\hline Organic carbon (\%) & 46.95 & 39.34 \\
\hline Nitrogen (as N\%) & 2.6 & 3.4 \\
\hline $\mathrm{C}: \mathrm{N}$ ratio & 18.1 & 11.1 \\
\hline
\end{tabular}


with $10 \%$ effluent. Strain $\mathrm{R}$ was used for effluent treatment study. This strain showed the alkali-tolerant laccase production during screening.

\subsection{Effluent Treatment Analysis}

Various parameters of the treated effluent were studied and compared taking day zero, Day 7 and Day 14 readings. Observations for all the parameters have been tabulated in Table 5 and Figure 3 indicates the colour changes observed for the respective readings.

\subsection{LC-MS Results}

Out of total 155 compounds detected by LCMS in untreated sample, 97 compounds

Table 5. Observation chart for the effluent treatment analysis.

\begin{tabular}{|c|c|c|c|c|c|c|c|c|c|}
\hline & \multicolumn{3}{|c|}{ Negative control } & \multicolumn{3}{|c|}{ Positive control } & \multicolumn{3}{|c|}{ Test } \\
\hline & Day zero & Day 7 & Day 14 & Day zero & Day 7 & Day 14 & Day zero & Day 7 & $\begin{array}{c}\text { Day } \\
14\end{array}$ \\
\hline \multicolumn{10}{|l|}{ Parameters } \\
\hline $\mathrm{pH}$ & 7.5 & 7.5 & 7.5 & 7.5 & 7.5 & 7.5 & 7.5 & 7.5 & 7.5 \\
\hline Odour & $\mathrm{D}$ & $\mathrm{D}$ & $\mathrm{D}$ & $\mathrm{D}$ & A & A & $\mathrm{D}$ & A & A \\
\hline Suspended solids & $\mathrm{N}$ & $\mathrm{N}$ & $\mathrm{N}$ & $\mathrm{N}$ & $\mathrm{N}$ & $\mathrm{N}$ & $\mathrm{N}$ & $\mathrm{N}$ & $\mathrm{N}$ \\
\hline Colour with naked eyes & Dirty green & Dirty green & Dirty green & Dirty green & Brown & Brown & Dirty green & Brown & Yellow \\
\hline $\begin{array}{c}\text { True colour with } \\
\text { photometer (PCU) }\end{array}$ & 3030 & 3000 & 2970 & 3030 & 2200 & 2100 & 3030 & 2110 & 1680 \\
\hline COD (ppm) & 39177 & 38790 & 37763 & 39177 & 38040 & 33110 & 39177 & 34140 & 31000 \\
\hline $\begin{array}{l}\text { Flocculationby wet } \\
\text { mount }\end{array}$ & - & - & - & - & + & ++ & - & + & ++ \\
\hline
\end{tabular}

Key: Negative control: Un-inoculated effluent; Positive control: Effluent inoculated with the commercial product designed for the treatment of the effluent; D: Disagreeable odour; A: Agreeable odour; N: No suspended solids; -: No flocculation seen when wet mount done; +: Flocculation seen; + +: Extent of flocculation increased as compared with earlier observations.

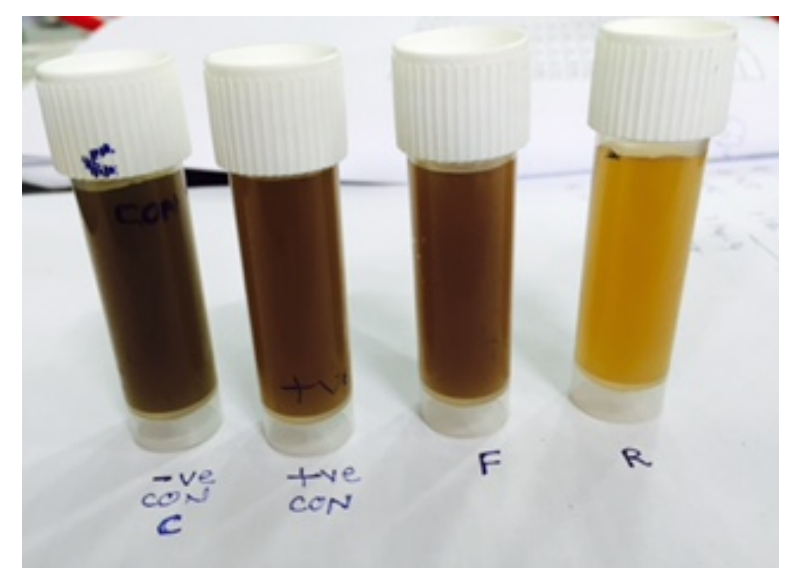

Key: Negative control: Un-inoculated effluent; Positive control: Effluent inoculated with the commercial product designed for the treatment of the effluent; F: Day 7 (7 days after effluent was treated with the test culture); R: Day 14 (14 days after effluent was treated with the test culture).

Figure 3. Negative and positive controls did not show any colour change after Day 7 and Day 14. Test culture showed considerable reduction in the colour of the effluent indicated by $\mathrm{F}$ and $\mathrm{R}$ respectively. 
were phenolics in nature. Out of total 175 compounds detected by LCMS in treated effluent sample, 80 compounds were phenolics in nature. It was found that 30 phenolics compounds were disappeared and found to be degraded in treated sample when compared with that of untreated sample. Also, 33 new phenolics compounds have been detected with different mass in treated effluent sample indicating the presence of degraded or modified compounds after enzymatic conversion. Overall, the results indicated the formation of degradation products by variety of chemical reactions. Also m/z values showed the reduction in ratio when side chain was eliminated or ring structure was opened up. In few cases, the intra-molecular re-arrangement has resulted in increase in the $\mathrm{m} / \mathrm{z}$ ratio.

\subsection{Phylogenetic Analysis of Alkali Tolerant and Laccase Producing Strain R}

The 16S rRNA gene from alkali tolerant and laccase producing strain $\mathrm{R}$ was sequenced. The partial sequence containing 1156 nucleotide base pairs showed close similarity with Streptomyces plicatus, Streptomyces enissocaesilis and Streptomyces rochei. The phylogenic tree constructed using ten matching sequences of 16S rRNA from NCBI data-base is shown in Figure 4. The evolutionary history was inferred using the UPGMA method [17]. The optimal tree with the sum of branch length $=0.01694915$ is shown. The percentage of replicate trees in which the associated taxa clustered together in the bootstrap test (100 replicates) is shown next to the branches [18]. The tree is drawn to scale, with branch lengths in the same units as those of the evolutionary distances used to infer the phylogenetic tree. The evolutionary distances were computed using the Maximum Composite Likelihood Method [19] and are in the units of the number of base substitutions per site. The analysis involved 12 nucleotide sequences.

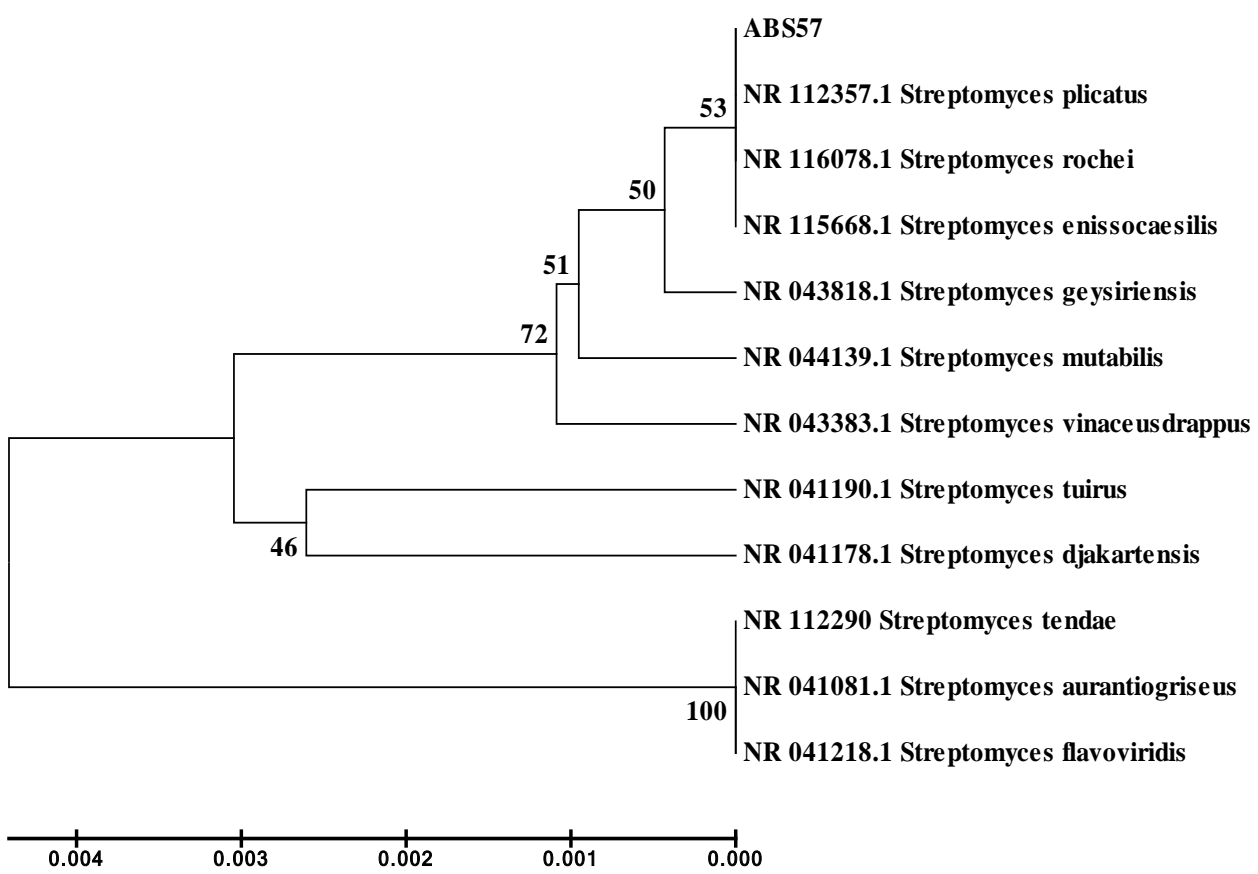

Figure 4. Evolutionary relationships of taxa (ABS57 is alkali tolerant and laccase producing isolated strain R). 
Codon positions included were $1^{\text {st }}+2^{\text {nd }}+3^{\text {rd }}+$ Noncoding. All ambiguous positions were removed for each sequence pair. There were a total of 1156 positions in the final dataset. Evolutionary analyses were conducted in MEGA6 [20].

\section{Conclusions}

\section{Composting}

Composting is a dynamic process involving many types of micro-organisms acting in succession to degrade organic matter. Today, there are various bacterial, fungal and actinobacterial species used worldwide as composting agents.

This study involved examining possibility of using only actinomycetes (without use of bacteria and fungi) for the composting process by finding consortium of such strains that could produce the key enzymes necessary for the degradation of cellulose, hemi-cellulose and lignin. A few actinomycete strains were shortlisted through screening and testing as described in detail above. Xylanase, laccase and cellulase enzymes produced by all the strains used in the consortium were thermo-tolerant and alkali-tolerant. The finally selected innovative consortium demonstrated promising activity and analysis showed the resultant composted material with desirable physical and chemical characteristics.

Actinomycetes have the ability to survive elevated $\mathrm{pH}$ and temperature conditions as much as bacteria and fungi. Their certain consortia can single-handedly produce all key enzymes for composting. In addition, they could produce antibiotics, which could control the growth of the plant pathogens present in the soil and hence, could be considered a better choice to bacteria and fungi. Given this promise, further study in respect of commercial scalability for their increased usage for solid waste management should be considered.

\section{Effluent treatment}

Many of the application studies to date are focused on enzymes from fungal sources. However, the fungal laccases which are mostly acidic in nature could not be used universally for all application purposes, especially for the treatment of effluents from different industries, largely due to the alkaline nature of the effluents. Under such situations, the enzymes from organisms like $S$. psammoticus with wide $\mathrm{pH}$ range could play a better role than the fungal counterparts (Niladevi and Prema 2008) [21].

Four strains of the bacterial genus Streptomyces $(S$. cyaneus, $S$. ipomoea, $S$. griseus and $S$. psammoticus) and the white-rot fungus Trametes versicolour were studied by Margot, et al. (2013) [22] for their ability to produce active extracellular laccase in biologically treated wastewater. Among the Streptomyces strains evaluated, only $S$. cyaneus produced extracellular laccase with sufficient activity. Laccase activity produced by $T$. versicolour was 20 times greater but laccase from $S$. cyaneus was active over wider $\mathrm{pH}$ and temperature ranges as compared with fungal laccase.

Current study used a strain of actinomycete having ability to produce laccase for the treatment of paper pulp effluent. Morphological characteristics indicated that the strain belonged to the genus Streptomyces. 16s RNA sequencing was carried out and BLAST results showed phylogenetic tree with 3 closely related Streptomyces species viz. Streptomyces plicatus, Streptomyces enissocaesilis and Streptomyces rochei. Streptomyces 
plicatus and Streptomyces enissocaesilis have been mainly studied as bio-control agents and no reports have indicated their ability to degrade organo-pollutants [23] [24].

Polychloro-phenol (PCP) derivatives are used as wood preservatives and thus, find their way into wastewater of the paper pulp industry. Streptomyces rochei 303 was found to be capable of de-chlorination of PCP derivatives by an inducible enzyme hydroxyquinol 1,2-dioxygenase [25]. Bioremediation of poly-aromatic hydrocarbons (PAH) has been reported indicating 28\% - 92\% degradation within 15 days at $100 \mathrm{ppm}$ level by Streptomyces rochei [26].

This strain has been tested positively for the production of enzyme laccase which is a ligninolytic enzyme playing key role in the degradation of PCP and/or PAH. Thus, it could be concluded that the strain under study was Streptomyces rochei. There is a mention of lignin degrading ability of Streptomyces rochei in the literature, but laccase production has not been reported [27]. Thus, this is the first report of laccase production by this actinomycete strain.

Promising results have been indicated by the Streptomyces sp. used (designated as R) in this degradation study at $\mathrm{pH} 7.5 \mathrm{After} 14$ days, $21 \%$ reduction in COD as compared with the $15.4 \%$ reduction given by the commercial product indicated promising role by the alkali-tolerant laccase producing strain under study. Reduction in true colour, odour and the extent of flocculation by the test organism showed favourable changes indicating the usefulness of the culture. LC MS report has shown the presence of degradation compounds (also comparing the $\mathrm{m} / \mathrm{z}$ values) formed after 7 and 14 days of incubation. Compounds showed the degradation of lignin components and other phenolic, non-phenolic components of the effluent by intra molecular rearrangement, oxidation and ring opening reactions. In conclusion, presence of degradation products could be co-related with the effective role of Streptomyces sp. in the degradation of effluent from paper pulp.

Overall, potent thermo-tolerant and alkali-tolerant actinomycete strains were successfully isolated and applied for bio-degradation of domestic agro-waste by composting and treatment of pulp-paper mill effluent. The consortium of selected actinomycete strains has been employed for this process. Further work is required to be carried out in order to develop the formulation containing these viable strains in combination with suitable carrier material and other beneficial microbes for commercial application.

\section{Acknowledgements}

Authors are thankful to the Head and Staff of Microbiology Department, Bhavan's College for providing the laboratory facility to carry out the preliminary screening work. Authors sincerely acknowledge Dr. Anuja Kenekar Murthi, Dr. Charu Fale, Rohan Shetty and Tiham Quraishi for the technical support extended by them during the application studies.

\section{References}

[1] Velasco, M.I., Campitelli, P.A., Ceppi, S.B. and Havel, J. (2004) Analysis of Humic Acid from Compost of Urban Wastes and Soil by Fluorescence Spectroscopy. AgriScientia, 21, 31-38.

[2] Trautmann, N. and Olynciw, E. (1996) Compost Microorganisms Cornell Waste Manage- 
ment Institute ${ }^{\oplus} 1996$. Cornell University, Ithaca, NY.

[3] Ryckeboer, J., Mergaert, J., Vaes, K., Klammer, S., De Clercq, D., Coosemans, J., Insam, H. and Swings, J. (2003) A Survey of Bacteria and Fungi Occurring during Composting and Self-Heating Processes. Ann Microbiology, 53, 349-410.

[4] Golueke, C.G. (1991) Principles of Composting. In: The Staff of Bio Cycle, Ed., The Art and Science of Composting, Journal of Waste Recycling, The JG Press Inc., Pennsylvania, 14-27.

[5] Paul Arnold Acadia University/Bio-Logic Environmental Systems (2011) Actinomycetes: The Sign of Composting Success. Compost Council of Canada.

[6] Golueke, G.G., Card, B.J. and McGauhey, P.H. (1954) A Critical Evaluation of Inoculums in Composting. Applied and Environmental Microbiology, 2, 45-53.

[7] Gray, K.R., Sherman, K. and Biddlestone, A.J. (1971) A Review of Composting-Part 1. Process Biochemistry, 6, 32-36.

[8] Waksman, S.A., Cordon, T.C. and Hulpoi, N. (1939) Influence of Temperature upon the Microbiological Population and Decomposition Processes in Compost of Stable Manure. Soil Science, 47, 83-114. https://doi.org/10.1097/00010694-193902000-00001

[9] Atchley, S. and Clark, J.B. (1979) Variability of Temperature, $\mathrm{pH}$ and Moisture in an Aerobic Composting Process. Applied and Environmental Microbiology, 38, 1040-1044.

[10] Sundberga, C., Yu, D., Franke-Whittle, I., Kauppi, S., Smårs, S., Insam, H., Romantschuk, M. and Jönsson, H. (2012) Effects of $\mathrm{pH}$ and Microbial Composition on Odour in Food Waste Composting. Waste Management, 33, 204-211. https://doi.org/10.1016/j.wasman.2012.09.017

[11] Partanen, P., Hultman, J., Paulin, L., Auvinen, P. and Romantschuk, M. (2010) Bacterial Diversity at Different Stages of the Composting Process. BMC Microbiology, 10, 94. https://doi.org/10.1186/1471-2180-10-94

[12] Yu, H., Zeng, G., Huang, H., Xi, X., Wang, R., Huang, D., Huang, G. and Li, J. (2007) Microbial Community Succession and Lignocellulose Degradation during Agricultural Waste Composting. Biodegradation, 18, 793-802. https://doi.org/10.1007/s10532-007-9108-8

[13] Karimi, K. (2015) Biofuel and Biorefinery technologies, Vol. 1-Lignocellulose Based Bioproducts. Springer, Berlin.

[14] Tuomela, M., Vikman, M., Hatakka, A. and Itavaara, M. (2000) Biodegradation of Lignin in a Compost Environment: A Review. Bioresource Technology, 72, 169-183. https://doi.org/10.1016/S0960-8524(99)00104-2

[15] Poincelot, R.P. (1972) The Biochemistry and Methodology of Compost. Bulletin 727, Connecticut Agricultural Experiment Station, New Haven.

[16] Viswanath, B., Rajesh, B., Janardhan, A., Kumar, A. and Narasimha, G. (2014), Fungal Laccases and Their Applications in Bioremediation. Enzyme Research, 2014, Article ID: 163242. https://doi.org/10.1155/2014/163242

[17] Sneath, P.H.A. and Sokal, R.R. (1973) Numerical Taxonomy. Freeman, San Francisco.

[18] Felsenstein, J. (1985) Confidence Limits on Phylogenies: An Approach Using the Bootstrap. Evolution, 39, 783-791. https://doi.org/10.2307/2408678

[19] Tamura, K., Nei, M. and Kumar, S. (2004) Prospects for Inferring Very Large Phylogenies by Using the Neighbor-Joining Method. Proceedings of the National Academy of Sciences of the United States of America, 101, 11030-11035. https://doi.org/10.1073/pnas.0404206101

[20] Tamura, K., Stecher, G., Peterson, D., Filipski, A. and Kumar, S. (2013) MEGA6: Molecular Evolutionary Genetics Analysis. Molecular Biology and Evolution, 30, 2725-2729. https://doi.org/10.1093/molbev/mst197

[21] Niladevi, N. and Prema, P. (2008) Immobilization of Laccase from Streptomyces psammo- 
ticus and Its Application in Phenol Removal Using Packed Bed Reactor. World Journal of Microbiology and Biotechnology, 24, 1215-1222. https://doi.org/10.1007/s11274-007-9598-x

[22] Jonas, M., Chloé, B., Julien, M., Paqui, B., Barry, D.A. and Christof, H. (2013) Bacterial versus Fungal Laccase: Potential for Micropollutant Degradation. AMB Express, 3, 63. http://www.amb-express.com/content/3/1/63 https://doi.org/10.1186/2191-0855-3-63

[23] Sirisha, B., Haritha, R., Mohan, Y.S.Y.V., Swathi, A. and Ramana, T. (2014) Molecular Characterization of Marine Streptomyces enissocaesilis Capable of $L$-Asparaginase Production. Bacteriology Journal, 4, 1-11. https://doi.org/10.3923/bj.2014.1.11

[24] Abd-Allah, E.F. (2001) Streptomyces plicatus as a Model Biocontrol Agent. Folia Microbiologica, 46, 309-314. https://doi.org/10.1007/BF02815619

[25] Golovleva, L.A., Zaborina, O., Pertsova, R., Baskunov, B., Schurukhin, Y. and Kuzmin, S. (1991) Degradation of Polychlorinated Phenols by Streptomyces rochei 303. Biodegradation, 2, 201-208. https://doi.org/10.1007/BF00124494

[26] Chaudhary, P., Sharma, R., Singh, S. and Nain, L. (2011) Bioremediation of PAH by Streptomyces sp. Bulletin of Environmental Contamination and Toxicology, 86, 268-271. https://doi.org/10.1007/s00128-011-0211-5

[27] Saini, A., Aggarwal, N.K., Sharma, A. and Yadav, A. (2015) Actinomycetes: A Source of Lignocellulolytic. Enzyme Research, 2015, Article ID: 279381.

https://doi.org/10.1155/2015/279381

Submit or recommend next manuscript to SCIRP and we will provide best service for you:

Accepting pre-submission inquiries through Email, Facebook, LinkedIn, Twitter, etc. A wide selection of journals (inclusive of 9 subjects, more than 200 journals)

Providing 24-hour high-quality service

User-friendly online submission system

Fair and swift peer-review system

Efficient typesetting and proofreading procedure

Display of the result of downloads and visits, as well as the number of cited articles

Maximum dissemination of your research work

Submit your manuscript at: http://papersubmission.scirp.org/

Or contact aim@scirp.org 